\title{
A new humic acid remedy with addition of silver nanoparticles
}

\author{
G.P. Alexandrova ${ }^{1}$, G. Dolmaa ${ }^{2}$, U.Enkhbadral ${ }^{3}$, G.L.Grishenko ${ }^{1}$, Sh.Tserenpil ${ }^{2}$, \\ B.G. Sukhov ${ }^{1}$, D. Regdel $^{1}$, B.A.Trofimov ${ }^{1}$
}

${ }^{1}$ Irkutsk Institute of Chemistry, Siberian Branch of RAS, Irkutsk, Russia

${ }^{2}$ Institute of Chemistry and Chemical Technology, MAS, Ulaanbaatar, Mongolia e-mail:dolmaa_g@yahoo.com

\begin{abstract}
Previously known biogenic stimulator humic acid (HA) was the subject of this current study and HA based new remediation was developed by addition of silver (Ag) nanoparticles in its macromolecule. Extracted HA from a healing mud was characterized and used as reducing agent for $\mathrm{Ag}$ ion as well as a stabilizer for the formed $\mathrm{Ag}$ nanoparticles. The properties of the obtained hybrid composite were examined by XRD, UV and FTIR spectroscopic techniques. The diameter of the nanoparticles in the HA polymer was up to $8.6 \mathrm{~nm}$ and they were identified to be metallic Ag.
\end{abstract}

Keywords: Composite; Healing mud; Humic acid; Silver nanoparticles

\section{INTRODUCTION}

A romatic nucleus and functional groups in the HA molecule react with cell walls of organisms and with receptors in a derma; furthermore, it shows a therapeutic effect by penetrating through tissues [1]. HA is a major proportion of organic matters in Mongolian healing mud [2] and it tends to form an organomineral particles. A hypothesis, therefore, was developed that HA may possess a stabilizing character for metal nanoparticles as other natural polymers do [3-4] and such behaviour has been recently investigated [5]. Humic substances from the healing mud differ from coal, turf and soil derived counterparts by their low molecular weight and high content of reactive functional groups [6]. Silver shows an antibacterial characteristic in addition to its chemical stability, good thermal and electrical conductivity and catalytic properties. Therefore organic and inorganic hydrid composites bearing Ag nanoparticles were synthesized and studied for a different purposes; for instance, as medical preparations, antimicrobial coatings for biomaterials, as well as film castings for electronic and optoelectronic devices. The formation of Ag nanoparticiples in a variety of polymers (e.g., natural and syntetic) has been examined as size and dispersion pattern of metal particles were unique for each case. Also natural polymers are biocompatible making them particularly interesting for researchers.

For obtaining metal nanoparticles, the most important controlling parameters include reducing agent type, stabilizer and the matrix in which nanoparticles are formed. Dendrimers usually take on a spherical three dimensional structure, which is very different from linear polymers. Additionally, it is predicted that HA may provide more active sites for stabilization of metal nanoparticles.

Akainge et al examined the formation of $\mathrm{Ag}$ nanoparticle in the presence of HA (i.e, from the fresh water and marine sediment) under environmentally relevant conditions (e.g., concentration, $\mathrm{pH}$ and temperature), and discussed the possible formation by the natural processes and their stability depending on HA 
characterization as well as environmental mobility [5].

Lipid, humic substances and water extracts from healing mud often used for therapy, among them HA based products are commercially well known. In this study, we aimed to develop a method to obtain a new prospective HA remedy based on nanotechnology approaches. It makes possible to overcome the disadvantages of conventional HA remedies by promoting biological activity, extended duration of effectiveness, elimination of toxicity and side effects, as well as increasing the selectiveness of treatments. In addition, it is one of a few studies on HA polymer as a stabilizer for metal nanoparticles.

\section{EXPERIMENTAL}

Materials and reagents. HA fraction was extracted from a sapropel peloid from Lake Gurvan nuur (geographical coordinates: $42^{\circ} 01^{\prime}$ $\mathrm{N} ; 111^{\circ} 40^{\prime} \mathrm{E}$ ), in Khentii province, Mongolia. $0.2 \mathrm{~N}$ sodium hydroxide $(\mathrm{NaOH})$ extraction was performed after $\mathrm{HCl}$ pretreatment and benzene/chloroform extraction as the peloid sample contains a significant amount of non HA organic matter [2]. The alkaline extract was decanted, centrifuged then passed through a nuclear filter with a pore size of $1 \mu \mathrm{m}$ (prepared at the Flerov Laboratory of Nuclear Reactions, Joint Institute for Nuclear Research, Dubna, Russia) to ensure the HA extract was free of clay particles. HA precipitated from the $\mathrm{NaOH}$ solution when acidified ( $\mathrm{pH} 2$ ) by using $0.1 \mathrm{~N}$ $\mathrm{HCl}$ solutions and washed by deionized water. Then dried and ground for further analyses and procedures. Silver nitrate $\left(\mathrm{AgNO}_{3}\right)$ and ethanol were all AR grade and were used as received from a supplier. Ultrapure water from an Arium ${ }^{\circledR b a s i c ~ s y s t e m ~(S a r t o r i u s ~ C o ., ~ L T D) ~ w a s ~}$ used throughout this work.

Synthesis of HA/Ag hybrid composite. Synthesis of HA/Ag organic and inorganic hybrid composite with antibacterial capacity was performed based on a method [7]. For each set of experimental trials, $400 \mathrm{mg}$ of peloid HA was dissolved in $6 \mathrm{~mL}$ of $1 \mathrm{~N} \mathrm{NaOH}$ solution and heated for 15 minutes. $\mathrm{AgNO}_{3}$ solutions with Ag concentrations ranging from 36-360 mg (Table 1) were added into the individual trials under constant stirring. Then the reaction mixture was filtered and ethanol added into it in order to precipitate the reaction product, which was then isolated by centrifugation. This product was washed with deionized water and ethanol as well. Here, ethanol was used as an agent to facilitate $\left[\mathrm{Ag}^{+}\right]$reduction to $\mathrm{Ag}^{0}[8]$ and to precipitate the resultant product from the solutions. Ag concentrations of the composites for each trial are given in Table 1 along with the amount of Ag initially taken for synthesis.

Analytical techniques. The peloid derived HA and synthetic composites were studied by ultimate analysis and their structures were investigated by using an FTIR spectroscopy, UV spectrometer and an X-ray diffractometer (XRD). The XRD patterns were recorded at a scanning rate of $4^{0} \mathrm{~min}^{-1}$ in the $2 \theta$ range of 20 $90^{\circ}$ using a Bruker D8 Advance diffractometer with $\mathrm{Cu} \mathrm{K}_{\alpha}$ radiation $(\lambda=1.54178 \mathrm{E})$. UV-Vis spectra were measured on a Specord UV-Vis spectrophotometer, while FTIR was measured using an RAM II Bruker Vertex70 spectrophotometer. In order to get quantitative results from the FTIR spectra, the intensities of the bands due to the oxygen containing functional groups were compared to those for aromatic $\left(1619 \mathrm{~cm}^{-1}\right)$ and aliphatic units (2920 $\mathrm{CM}^{-1}$ ) (Table 2). The Ag concentration was measured using an atomic adsorption spectrophotometer (AAS) Perkin-Elmer Analyst 200.

\section{RESULTS AND DISCUSSION}

In terms of molecular structure, HA is an aromatic non organized polymer containing carboxylic, phenolic $\mathrm{OH}$, quinon, hydroxyl, methoxyl, aldehyde, keton and enolic group as well as nitrogen and sulfur (often found in thiol group) atoms. Its main structural skeleton is alkyl and polyfunctional groups attached to condensed aromatic rings, with polysaccharides and polypeptides associated into it. We found efficient HA purification from clay particles using the nuclear filter and its ash content was negligible. It consisted of $48.9 \% \mathrm{C}, 5.4 \% \mathrm{H}$, $5.0 \% \mathrm{~N}, 1.3 \% \mathrm{Cl}$ (percentages based on weight), and the molar ratio of $\mathrm{H} / \mathrm{C}$ was 1.325 , which indicates higher aliphaticity than typical value for other HAs from coal and soil specimens as reported by the International Humic Substances Society. Ag content in the hybrid composites fluctuated from 5.5 $\mathrm{g} / 100 \mathrm{~g}^{-1}$ to $24.8 \mathrm{~g} 100 \mathrm{~g} \mathrm{~g}^{-1}$, where the initial ratio of $\mathrm{Ag}^{+}: \mathrm{HA}$ ranged between 1:1 to $1: 11$ (Table 1). 
Table 1. Silver concentrations in HA matrix

\begin{tabular}{|c|c|c|c|}
\hline Trials & $\begin{array}{c}\text { Added } \\
\text { silver } \\
\text { amounts, } \\
\mathrm{mg}\end{array}$ & $\begin{array}{c}\text { The ratio of } \\
\mathrm{Ag}+\mathrm{HA}\end{array}$ & $\begin{array}{c}\text { Silver } \\
\text { concentration } \\
\mathrm{s}(\mathrm{g} / 100 \mathrm{~g} \\
\text { composite) }\end{array}$ \\
\hline Trial 5 & 36 & $1: 11.1$ & 5.5 \\
\hline Trial 3 & 72 & $1: 5.6$ & 9.5 \\
\hline Trial 7 & 108 & $1: 3.7$ & 12.0 \\
\hline Trial 6 & 144 & $1: 2.8$ & 15.6 \\
\hline Trial 8 & 360 & $1: 1.1$ & 24.8 \\
\hline
\end{tabular}

In FTIR spectrum (Fig.1), the peloid HA showed an intense band at $3425 \mathrm{~cm}^{-1}$ that was due to hydroxyl groups, and bands at $2920 \mathrm{~cm}^{-1}$ and $2850 \mathrm{~cm}^{-1}$ which attributed to the $\mathrm{C}-\mathrm{H}$ of methyl and methylene groups. Bands at 16191591 , and $1379 \mathrm{~cm}^{-1}$ were due to benzene ring with $\mathrm{C}=\mathrm{O}$ units. The $\mathrm{CO}$ in ether groups appeared at $1228 \mathrm{~cm}^{-1}$, and in hydrocarbons registered between 1076 and $1041 \mathrm{~cm}^{-1}$ [8]. The FTIR spectrum of the parent HA and the obtained hybrid composites (not shown here) were similar, indicating that the HA molecular structure remained virtually unchanged after reaction. The parametrical calculation of HA structure from FTIR spectra revealed that the dominant oxygen bearing moieties were hydroxyl groups of phenol and carbohydrate, and carbonyls $(\mathrm{C}-\mathrm{O})$ of ether and carbohydrate (Table 2).

Table 2. Comparison of band intensities in FTIR spectra of the peloid-derived HA

\begin{tabular}{|c|c|c|c|}
\hline $\begin{array}{c}\text { Functional groups } \\
\text { and }\end{array}$ & \multicolumn{2}{|c|}{ Band intensity } & Ratio of \\
\hline its corresponding & $\left(\mathrm{I}_{\mathrm{X} 1}\right)$ & $\left(\mathrm{I}_{\mathrm{X} 2}\right)$ & $. \mathrm{I}_{\mathrm{X} 1} / \mathrm{I}_{\mathrm{X} 2}$ \\
\hline wavelength $\left(\mathrm{X}_{\mathrm{I}} / \mathrm{X}_{2}\right)$ & $(\mathbf{I X I})$ & $(\mathbf{I X})$ & \\
\hline $\mathrm{OH}_{3425} / \mathrm{C}=\mathrm{C}_{1619}$ & 44 & 52 & 0.84 \\
\hline $\mathrm{Calk}_{2920} / \mathrm{C}=\mathrm{C}_{1619}$ & 52 & 52 & 1.00 \\
\hline $\mathrm{CO}_{1228} / \mathrm{C}=\mathrm{C}_{1619}$ & 57 & 52 & 1.10 \\
\hline $\mathrm{OH}_{3425} / \mathrm{Calk} k_{2920}$ & 44 & 52 & 0.85 \\
\hline $\mathrm{C}_{1228} / \mathrm{Calk}_{2920}$ & 57 & 52 & 1.10 \\
\hline
\end{tabular}

plasmon band appeared at around $400 \mathrm{~nm}$. Similarly, study on Ag nanoparticle formation in the presence of various origins of HAs (i.e, the fresh water and marine sediment HAs) showed the surface plasma resonance peak at around 400-420 nm [5]. These authors concluded that the aliphatic predominant HAs (e.g., sedimentary) more readily reduced $\mathrm{Ag}+$ than did aromatic dominant HAs (i.e., from soils) and formed Ag nanoparticles were stable. The variation in peak wavelength may result from particle size and agglomeration state of
Therefore, the ratio of hydrophilic and hydrophobic moieties $\left(\mathrm{OH}_{3425} / \mathrm{Calk}_{2920}\right)$ of HA was 0.85 , while the ratio of aliphatic and aromatic $\left(\mathrm{Calk}_{2920} / \mathrm{C}=\mathrm{C}_{1619}\right)$ units was 1 .
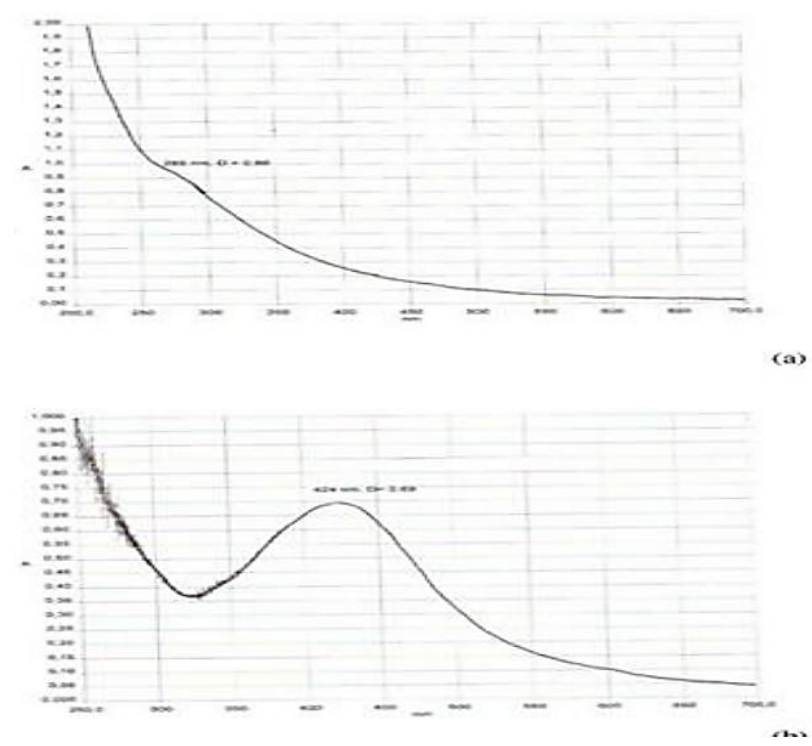

Figure 2. UV-Vis spectra of (a). HA in sodium hydroxide solution and (b). HA matrix contains Ag nanopartic

In the UV-Vis spectrum of peloid derived HA, an absorption maximum at $285 \mathrm{~nm}$ with high optic density was observed and that was assigned to $-\mathrm{OH}$ groups in phenolic moiety (Fig.2.a). But in the HA/Ag spectrum (for trial 8), an absorption peak was observed at $424 \mathrm{~nm}$ (Fig.2.b) which is associated with the surface plasmon resonance of nanoparticles of metal Ag. This absorption maximum in the hybrid composite resulted from electron transmission of excited metals. It is believed that Ag ion was reduced in the presence of HA by its reducing sites [9]. An earlier work on $\mathrm{HA} / \mathrm{Ag}$ composite was studied this composite as a colorimetric sensor of herbicide [10]; the average size of nanoparticles found to be $5 \mathrm{~nm}$ and the surface

nanoparticles were calculated by the 111 line; and a parameters of unit cell ranged 4.059 (1)4.077 (1) $\mathrm{A}^{\mathrm{o}}$; and the average coherent scattering region of $\mathrm{Ag}$ nanoparticles was 8.6 $\mathrm{nm}$ in the HA/Ag composite.Aggregate resistant of colloidal system is defined by several parameters including small particles solvatation and repulsion of electrical statistic force. It is certain that HA polyanions in aqueous solution react with positively charged $\mathrm{Ag}$. This interaction could result in coagulation of the system. However, the colloid system was stable 
formed nanoparticles. The surface plasmon bands for nano-sized $\mathrm{Ag}$ formed in natural rubber matrix were ranged between 425-484 nm [4], while it was at about $418 \mathrm{~nm}$ for Ag/polyvinyl alcohol [11] composite, where particles sizes were $4-10 \mathrm{~nm}$ and $<10 \mathrm{~nm}$, respectively. in the given ratios of HA:Ag. This showed that HA functional groups occupy all possible coordination positions on the surface of metal nanoparticles. HA associates to the nanoparticle surface and increases the hydrophilic character of products; this will sustain its stability in

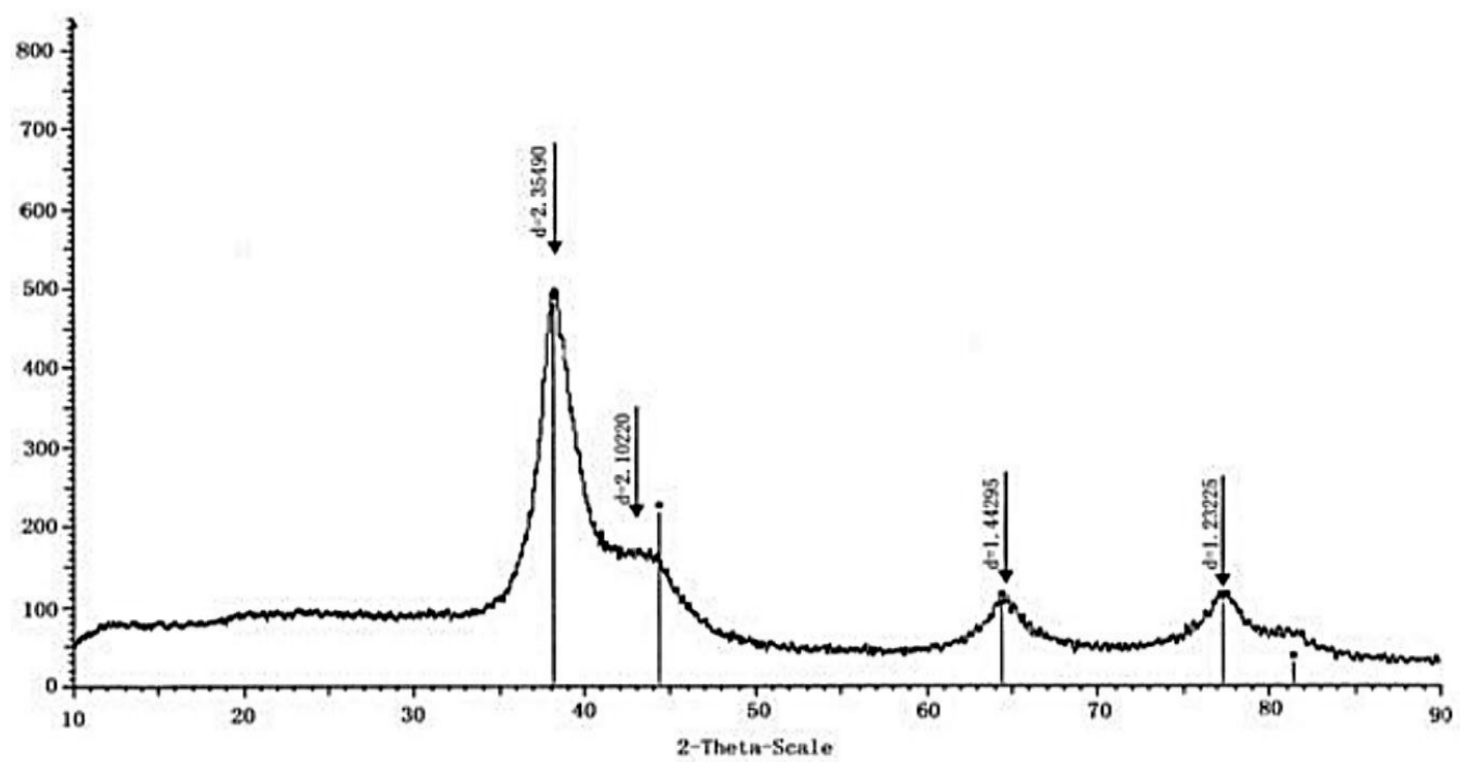

Figure.3. XRD pattern of Ag nanoparticles stabilized within peloid HA

The XRD spectrum, in Fig.3 (trial 8), was consistent with published data on nano-sized metal Ag [7] and demonstrated the existence of $\mathrm{Ag}^{0}$ in the product. All the prominent peaks at $2 \theta$ values of about $38,44.2,64.4,77.6$ and $81.6_{0}$ represent the 111, 200, 220, 311 and 222 Bragg's reflections of $\mathrm{Ag}$ crystal. The diffraction line for the first precursor (i.e., $\mathrm{Ag}+$ ) was not observed, showing that the reduction process was completed. Also, diffraction line intensity and distance between planes were in good agreement with the standard lines of Ag. Both UV-Vis spectra and XRD analysis confirmed that the synthesized hybrid product contains $\mathrm{Ag}^{0}$. Here, reduction of $\mathrm{Ag}^{+}$could be induced by oxidation of phenolic hydroxyl and carbonyl groups in HA composition. The average unit cell parameters of $\mathrm{Ag}$ aqueous solution. The resultant $\mathrm{HA} / \mathrm{Ag}$ hybrid composite could be essential to improve the properties of HA preparations because of Ag's antibacterial properties and the enhanced solubility of the product.

\section{CONCLUSIONS}

We sought to develop a new HA remedy containing $\mathrm{Ag}$ nanoparticles. In this work, ethanol was used to precipitate the resultant product due to the stabilizer's (i.e., HA) analytical character and also to facilitate the reduction of $\mathrm{Ag}^{+}$to $\mathrm{Ag}^{0}$. The $\mathrm{Ag}$ nanoparticles formation within HA polymer was determined by analytical techniques and the average size of metal particles were determined to be $8.6 \mathrm{~nm}$. This advanced HA/Ag hybrid composite, will contribute to overcome some problems observed in traditional HA based remedies. 


\section{REFERENCES}

1. E.F. Levitskii, D.I. Kuzmenko and B.I. Laptev: Complex application of natural healing factors and field of constant magnets in experiments and clinics, Published by the Tomsk University, Tomsk, 2001.

2. Sh. Tserenpil, G. Dolmaa and M.G. Voronkov: Appl. Clay Sci., 2010, 49, 55.

3. M. Adlim, M.A. Bakar and K.W. Liew: J. Mol. Catal. A: Chem., 2004, 212, 141.

4. N.H.H. Abu Bakar, J. Ismail and M. Abu Bakar: Mater. Chem.Phys., 2007, 104, 283.

5. N. Akaighe, R.I.MacCuspie, D.A. Navarro, D.S. Aga, S. Banerjee, M. Sohn and V.K. Sharma: Environ. Sci. Technol., 2011, 45, 3895.
6. Z. F. Kosyanova, D.S. Orlov and Ya. M. Ammosova: Humic substances in biosphere. Nauka, Moscow, 1993.

7. G.P. Alexandrova, G.L. Grishenko, T. Fadeeva, S. A. Medvedeva, B. G. Sukhov and B. A. Trofimov: Russian Patent №2 278 669, 2006.

8. L.A. Kazitsina and N.B. Kupletskaya: Applications of UV-, IR-, NMR- and massspectroscopy in organic chemistry. Pub. MGU, Moscow, 1979.

9. Z. Struyk and G. Sposito: Geoderma, 2001, $102,329$.

10. S. T. Dubas and V. Pimpan: Mater. Lett. 2008, 62, 2661.

11. P. K. Khanna, N. Singh, S. Charan, V.V.V.S. Subbarao, R. Gokhale and U. P. Mulik: 2005, 93, 117. 